\title{
Knockdown of Nurrl in the rat hippocampus: Implications to spatial discrimination learning and memory
}

\author{
Wanda I. Colón-Cesario, Michelle M. Martínez-Montemayor, Sohaira Morales, \\ Jahaira Félix, Juan Cruz, Monique Adorno, Lixmar Pereira, Nydia Colón, \\ Carmen S. Maldonado-Vlaar, and Sandra Peña de Ortiz ${ }^{1}$
}

Department of Biology, University of Puerto Rico, San Juan 00931-3360, Puerto Rico

\begin{abstract}
Nurrl expression is up-regulated in the brain following associative learning experiences, but its relevance to cognitive processes remains unclear. In these studies, rats initially received bilateral hippocampal infusions of control or antisense oligodeoxynucleotides (ODNs) $1 \mathrm{~h}$ prior to training in a holeboard spatial discrimination task. Such pre-training infusions of nurrl antisense ODNs caused a moderate effect in learning the task and also impaired LTM tested $7 \mathrm{~d}$ later. In a second experiment, ODN infusions were given immediately after the animals had received two sessions of training, during which all animals showed normal learning. Although antisense treated rats were significantly impaired during the post-infusion stages of acquisition of the task, no group differences were observed during the LTM test given $7 \mathrm{~d}$ later. These animals were subjected $3 \mathrm{~d}$ later to reversal training in the same maze in the absence of any additional treatments. Remarkably, rats previously treated with antisense ODNs displayed perseveration: The animals were fixated with the previously learned pattern of baited holes, causing them to be significantly impaired in the extinction of acquired spatial preferences and future learning. We postulate that Nurrl function in the hippocampus is important for normal cognitive processes.
\end{abstract}

Learning requires the continued ability of the brain to establish new synaptic configurations and could be viewed as the continuation of the developmental process. Nurr1 (also known as HZF-3) (Peña de Ortiz and Jamieson Jr. 1996; Peña de Ortiz et al. 2000; Ge et al. 2003) is a member of the inducible nuclear receptor family of transcription factors (Law et al. 1992; Xing et al. 1997; Honkaniemi and Sharp 1999; Wang et al. 2003) that has been shown to play a key role in neural development. Specifically, expression of nurr1 is critical for the development of mesencephalic dopaminergic precursor neurons (Zetterstrom et al. 1997; Castillo et al. 1998; Saucedo-Cardenas et al. 1998). Thus, nurr1 has been implicated in the pathogenesis of dopamine-related neuropsychiatric disorders, such as Parkinson's disease, cocaine addiction, and schizophrenia (Bannon et al. 2002; Eells 2003; Jankovic et al. 2005; Chu et al. 2006). However, while human genetic studies have found polymorphisms and mutations in the nurr1 gene of patients with schizophrenia (Buervenich et al. 2000; Chen et al. 2001), there is still no clear association between such genetic variations and this disorder (Carmine et al. 2003; Iwayama-Shigeno et al. 2003; Ruano et al. 2004; Feng et al. 2005). On the other hand, recent studies showed that nurr1 mutant heterozygous mice subjected to post-weaning isolation display a disruption of prepulse inhibition (a model of sensorimotor gating in the brain that is disrupted in patients with schizophrenia) (for review, see Van den Buuse et al. 2003), which is possibly related to decreased dopamine neurotransmission in the mutant heterozygous genotype (Eells et al. 2006).

Disordered cognitive processes stemming from impaired hippocampal function are an important part of the positive

\footnotetext{
1 Corresponding author.

E-mail sandra@hpcf.upr.edu; fax 787-764-3875.

Article is online at http://www.learnmem.org/cgi/doi/10.1101/lm.407706.
}

symptoms in schizophrenia (Harvey et al. 2001; Antonova et al. 2004; Sweatt 2004; Johnson 2005). The holeboard spatial discrimination task was initially developed to study thought disorders in animal models of schizophrenia (Oades and Isaacson 1978). In this hippocampal-dependent task (Oades 1981), animals learn to discriminate between relevant versus irrelevant stimuli, a cognitive process that is impaired in schizophrenia (Gray and Snowden 2005). Our previous studies showed increased rat hippocampal nurr1 mRNA levels after the first and third training sessions in this task (Peña de Ortiz et al. 2000). The results reported here suggest that suppression of the hippocampal expression of Nurr1 during acquisition of the holeboard spatial discrimination task results in long-lasting cognitive dysfunction.

\section{Results}

One-day version of the spatial discrimination holeboard task

Initially, a new version of the holeboard spatial discrimination task was established in order to perform a single intrahippocampal microinjection of oligodeoxynucleotides (ODNs). Foodrestricted animals were trained in the 1-d modified version of the task, which consisted of four consecutive training sessions separated by a 1-h rest period. Rats subjected to this task efficiently learned to visit a specific pattern of baited holes at the end of $1 \mathrm{~d}$ of training and were shown to use an allocentric strategy to acquire and remember the task (data not shown). That is, accurate hole visits during the retention test depended on the use of extramaze spatial cues, consistent with our previous findings with the standard version of this task (Peña de Ortiz et al. 2000). 


\section{Hippocampal Nurrl antisense knockdown experiment design}

Figure 1A shows the design of Experiment 1 in which the effects of pre-training hippocampal infusions of nurr1 antisense ODNs were tested on acquisition and retention of spatial discrimination. Free exploration in the fully baited maze was allowed on the day prior to spatial training. On the next day, animals received bilateral hippocampal infusions of saline, sense, or antisense ODNs $1 \mathrm{~h}$ before subjecting them to the 1 -d version of the holeboard spatial discrimination task. Next, one group of rats was sacrificed immediately after session 4 , and their brains used for immunohistochemistry analysis, while others were allowed to rest for $7 \mathrm{~d}$ and then received a retention test in order to assess the effects of treatment on LTM. For Experiment 2 (Fig. 1B), we targeted the learning-induced hippocampal expression of Nurr1. As in Experiment 1, free exploration in the fully baited maze was allowed on the day prior to spatial training. On the training day, animals initially received two sessions without prior treatment. Sense or antisense ODN infusions were given immediately after session 2 . The following 2 sessions were then resumed $1 \mathrm{~h}$ later. In total, rats received four training sessions, each separated by a 1 -h rest period, as in the pre-training ODN infusion studies (Fig. 1A). Next, one group of rats was sacrificed immediately after session 4 and their brains used for immunoblotting analysis, while others were allowed to rest for $7 \mathrm{~d}$ and then received a retention test in order to assess the effects of treatment on LTM. Finally, Experiment 3 (Fig. 1C) was done to further assess the long-term impact of mid-training nurr1 hippocampal knockdown on spatial learning and memory (Experiment 2, Fig. 1B). After the retention test on day 8 , all animals reaching the retention test in Experiment 2 were allowed to rest for $3 \mathrm{~d}$ and were then subjected to a reversal learning protocol in the same holeboard maze, but this time without ODN microinfusions. Animals were subjected to reversal learning by requiring them to acquire a new pattern of food location. Animals received four sessions of training each separated by a 1-h rest period. A retention test was given $7 \mathrm{~d}$ later.

\section{Histological analysis}

The correct placement of cannulas within the hippocampal CA3 area was corroborated by inspection of coronal serial sections subjected to thionin staining. The distribution of cannula placements directed toward the CA3 subregions across the anterior-posterior coordinates covered from -3.14 to -3.60 $\mathrm{mm}$ from bregma (Fig. 2A). We also examined the diffusion and approximate stability of nurr 1 antisense ODNs in the dorsal hippocampus. The infused fluoreversal training. rescein isothiocyanate-labeled ODN (FITC-ODN) could be detected at both 1 and $3 \mathrm{~h}$ post-injection within CA3 pyramidal cells of the dorsal hippocampus (Fig. 2B). Little or no diffusion was observed within the pyramidal CA1 or CA2 layers. These findings are important because of studies indicating that both the CA1 and CA3 subregions of the hippocampal formation are necessary for spatial learning and memory (Stubley-Weatherly et al. 1996; Florian and Roullet 2004; Lee and Kesner 2004a; Daumas et al. 2005; Lee et al. 2005). Occasionally, diffusion extended into the dentate gyrus (DG) and/or the dorsal thalamus, which are brain areas shown to display low or no expression of Nurr1 (Xiao et al. 1996; Zetterstrom et al. 1996). No diffusion was observed into ventral brain regions.

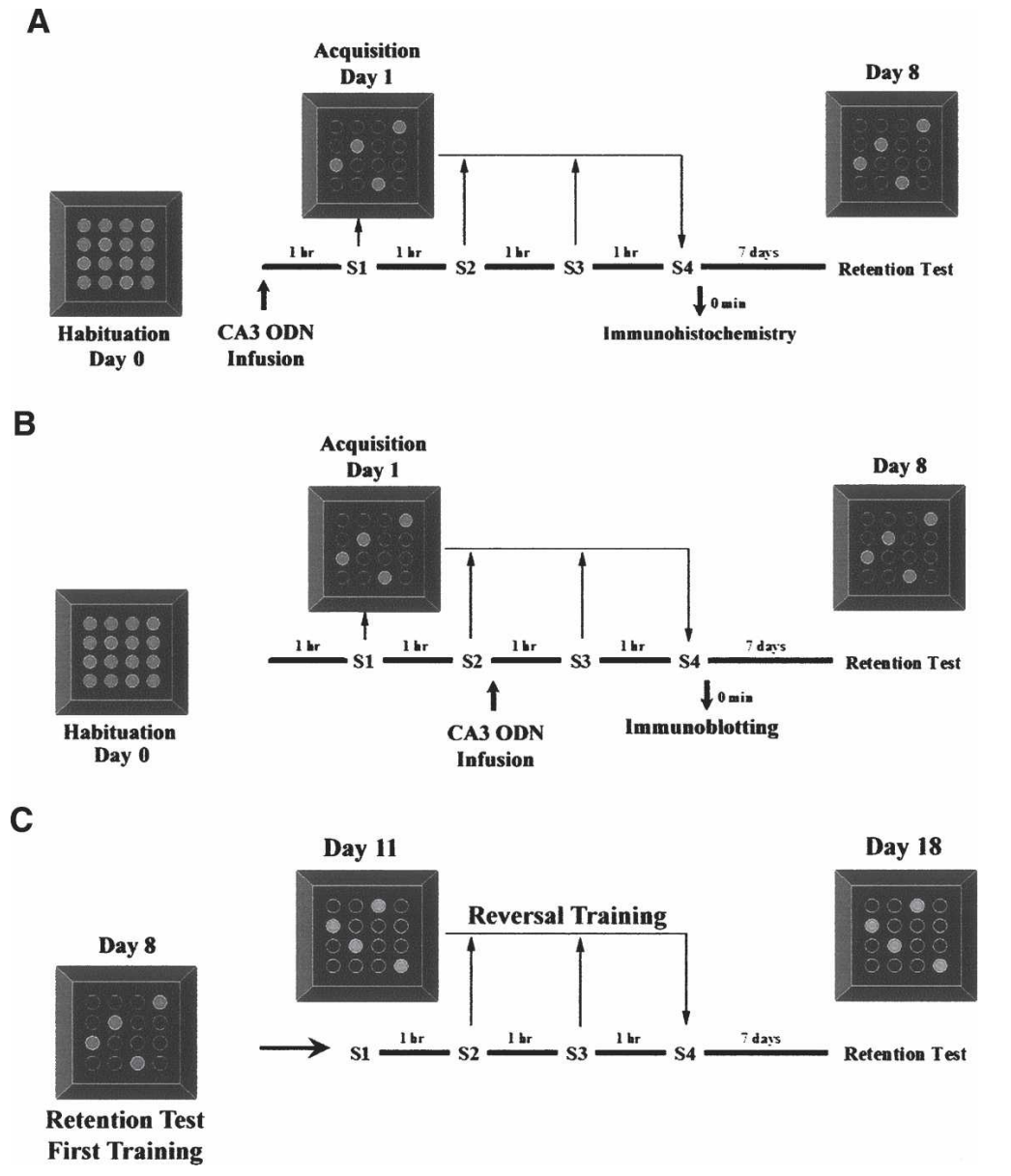

Figure 1. Experimental design for pre- and mid-training hippocampal Nurr1 knockdown. (A) Experiment 1. Effects of pre-training nurr 1 antisense hippocampal infusions on acquisition and retention of spatial learning. Animals were able to freely explore the baited maze $1 \mathrm{~d}$ before spatial training. On the training day, bilateral infusions of saline, sense, or antisense ODNs were directed to the CA3 region $1 \mathrm{~h}$ before training. Animals received four training sessions each separated by a $1-\mathrm{h}$ rest period. One group of rats was sacrificed immediately after the fourth session, and brains were used for Nurr1 immunohistochemical analysis, while a second group of rats was subjected to a retention test $7 \mathrm{~d}$ post-training to assess LTM. (B) Experiment 2. Effects of mid-training nurr1 antisense hippocampal infusions on acquisition and retention of spatial learning. Animals were habituated as in Experiment 1. However, on the training day, animals received two training sessions, followed immediately by bilateral infusions of sense or antisense ODNs to the CA3 region. Training was continued as in Experiment 1. A group of animals was sacrificed immediately after the fourth session, and brains were used for immunoblotting analysis. A separate group of animals was subjected to a retention test $7 \mathrm{~d}$ posttraining to assess LTM. (C) Experiment 3. Long-term impact of mid-training nurr1 antisense hippocampal infusions on spatial learning and memory. Rats in Experiment 2 were allowed to rest for $3 \mathrm{~d}$ after their retention test. These rats were then subjected to a reversal task requiring them to learn a new pattern of food location within the same maze, but without additional ODN treatment. Animals received four training sessions, each separated by a 1-h rest period. A retention test was given $7 \mathrm{~d}$ after 
A

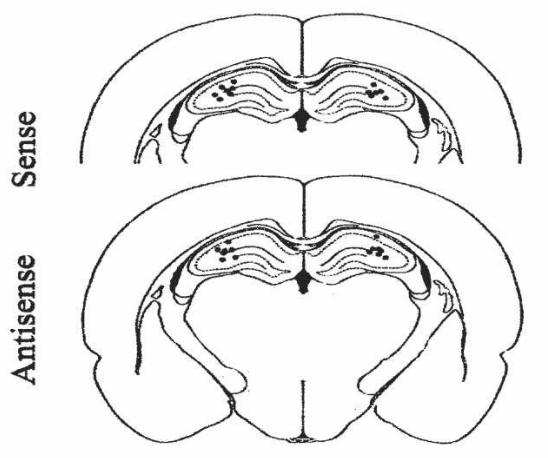

C

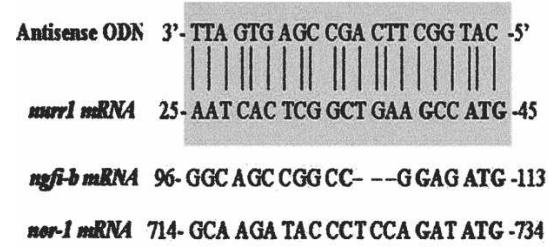

B

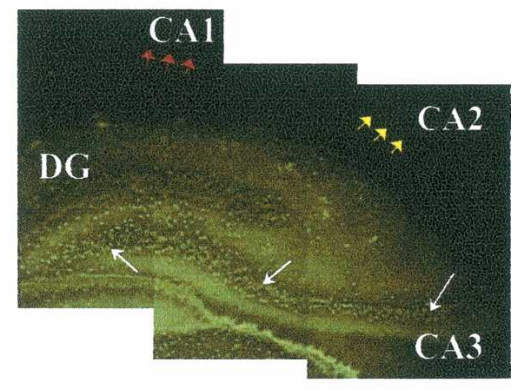

D

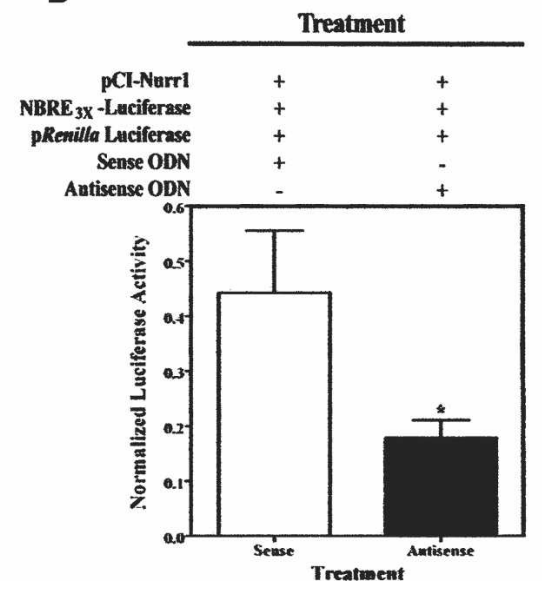

Figure 2. In vivo brain diffusion studies and in vitro studies of antisense ODN molecular efficiency. (A) Verification of cannulae placements. Rats were decapitated immediately after the end of all behavioral treatments. Brains were dissected, serial coronal sections were obtained, and these were subjected to Nissl staining with thionin. Drawings represent the area of $-3.3 \mathrm{~mm}$ from bregma. The dots represent the estimated sites of cannula placements. The analysis presented includes representative data from our studies with CA3 sense ODN-treated rats $(N=7)$ and CA3 antisense ODN-treated rats $(N=7)$. (B) The composite photomicrograph depicts the infused fluorescein isothiocyanatelabeled ODN (FITC-ODN) detected at $3 \mathrm{~h}$ post-injection within CA3 pyramidal cells of the dorsal hippocampus (white arrows). Occasional diffusion extended to the DG, a brain region shown to display low Nurr1 protein expression. Red and yellow arrows display little or no diffusion within the CA1 or CA2 regions, respectively. (C) Alignment of the designed nurr1 antisense ODN sequence shows a perfect match with rat nurr1 mRNA (shaded area), but not for the other two members of the Nur family, ngfi- $b$ and nor-1. The start codon on each sequence is in bold. (D) In vitro nurr1 antisense ODN treatment in cotransfected AD293 kidney cells. Nurr1 antisense ODN-treated cells had lower levels of luciferase activity than sense ODN-treated cells $\left({ }^{*} P<0.05\right)$. Luciferase activity was normalized to Renilla luciferase activity. Data are presented as the means \pm SEM (bars) of independently transfected cultures ( $N=6$ transfections).

\section{Molecular analysis}

nurrl antisense ODNs block Nurrl-mediated transcriptional activation

The designed antisense ODN, targeting the start codon of rat nurr1 mRNA, showed no homology with any other sequence in GenBank, including the other two members of the rat Nur family, $n g f i-B$ and $n o r-1$ (Fig. 2C). The nurr1 antisense and sense ODN sequences showed a perfect match with the rat nurr1 (hzf-3) mRNA corresponding to nucleotides 25-45 (GenBank accession no. U01146). The 3 '-end of our designed sequences overlapped the initiation codon in nurr1 mRNA. To analyze the effectiveness and specificity of the nurr1 antisense ODNs, we cotransfected AD293 cells, which do not express endogenous Nurr1, with an NBRE-luciferase reporter construct, a control Renilla luciferase construct, and a plasmid directing the expression of mouse Nurr1 (pCI-Nurr1), which differs from rat Nurr1 in only one base pair within the $5^{\prime}$-region of the sequence targeted by the antisense
ODN (data not shown). The NGFI-B response element (NBRE, AAAGGTCA) is the known binding site for members of the Nur family of orphan nuclear receptors that includes NGFI-B, NOR-1, and Nurr1 (Wilson et al. 1991; Peña de Ortiz and Jamieson Jr. 1996; Cheng et al. 1997). Transfected cells were treated with antisense or sense ODNs $24 \mathrm{~h}$ later. Approximately $24 \mathrm{~h}$ after ODN treatment, cells were harvested for detection of luciferase and Renilla luciferase activity. The results are shown in Figure 2D. Protein extracts prepared from cells treated with nurr1 antisense ODNs displayed significantly lower levels of luciferase activity than extracts prepared from sense ODN-treated cells (Student's $t$-test: $t_{10}=2.234,{ }^{*} P<0.05$; $N=6$ each group). The results demonstrate the effectiveness of our antisense ODNs in suppressing the expression and transactivation function of Nurr1. Importantly, neither sense nor antisense ODNs affected cell survival in culture.

\section{Hippocampal Nurrl antisense knockdown}

Immunohistochemistry analysis was used to verify that any observed behavioral effects of hippocampal pre-training infusions of nurr1 antisense ODNs (Experiment 1 , see Fig. 1A) were due to suppressed levels of Nurr1 protein $(N=5-7)$. Expression was quantified as the number of Nurr1-positive nuclei. As seen in Figure 3A, antisense ODN treatment significantly decreased the number of Nurr1-positive nuclei in the CA3 hippocampal subregion, compared to sense ODN infusions (Student's $t$-test: $\left.t_{10}=3.203,{ }^{* *} P<0.01\right)$. No significant difference was observed in the number of Nurr1-immunopositive granule cells of the dentate gyrus (DG) (data not shown). Thus, the observed behavioral effects cannot be attributed to suppression of Nurr1 expression within the DG, which normally shows low or no expression of the protein (Xiao et al. 1996; Zetterstrom et al. 1996).

For all Western blotting experiments (Experiment 2, see Fig. 1B), values for Nurr1 immunoreactivity were normalized to levels of $\beta$-Actin in order to account for variations in gel loading. Protein was extracted from pooled dorsal hippocampi of three rats (data not shown) or from pooled CA3 tissue obtained from the vicinity of the tip of the injection cannula from three rat brains. The results of immunoblotting assays from protein extracts prepared from tissue close to the injection site showed reduced Nurr1 levels in hippocampal antisense, compared to sense, treated rats (Student $t$-test, $t_{2}=9.743,{ }^{*} P<0.05 ; N=2$ pools of tissue prepared from three animals each) (Fig. 3B,D). Importantly, no significant differences were observed for c-Fos (Student $t$-test, $t_{2}=0.5605, P>0.05$ ) (Fig. 3C) or $\beta$-Actin (Fig. 3D) protein expression between the groups, indicating the specificity of the effect of the nurr1 antisense ODN. Overall, our data support the 
notion that the cognitive impairments of nurr1 ODN antisense treated rats are related to suppression of hippocampal Nurr1 expression.

\section{Behavioral analysis}

\section{Pre-training infusions}

The behavioral results obtained in Experiment 1 are shown in Figure 4, A and B. Only the data obtained for animals subjected to both acquisition and retention are shown. Two-Way repeated measures ANOVA of the acquisition (sessions 1-4) and retention (session 5) data confirmed that all groups [saline $(N=8)$, sense $(N=7)$, or antisense $(N=6)$ ] displayed spatial learning as shown by a significant decrease in the searching time (Fig. 4A) and the number of errors (Fig. 4B) observed throughout training (sessions factor: $F_{4,72}=39.09$, ${ }^{* *} P<0.0001 ;$ and $F_{4,72}=14.57$, ${ }^{* * *} P<0.0001$, respectively). The repeated measures analysis also established a significant effect of subject matching throughout sessions $\left(F_{21,84}=2.126,{ }^{* *} P<0.01\right)$. With respect to searching time (or the latency to find the four baited holes), no overall difference was detected between groups throughout acquisition and retention (Two-Way repeated measures ANOVA; treatment factor: $F_{2,72}=2.375, P>0.1$ ) (Fig. 4A). These results suggest that the antisense ODN treatment did not cause alterations in the states of arousal, activity, or motor or sensory systems of the animals, compared to sense ODNtreated animals. On the other hand, as seen in Figure 4B, we observed a moderate, yet significant, increase in the number of errors committed by the antisense treated rats, compared to the control groups (Two-Way repeated measures ANOVA; treatment factor: $\left.F_{2,72}=5.709,{ }^{*} P<0.05\right)$. Although multiple comparisons post-testing did not identify specific significant differences between the groups during particular sessions, the plotted data suggest that antisense treated rats were impaired during acquisition, which probably resulted in impaired LTM observed during the retention test. Similar acquisition results as those reported above, with respect to searching time (Two-Way repeated measures ANOVA; sessions factor: $F_{3,51}=51.52,{ }^{* *} P<0.0001$; treatment factor: $F_{1,51}=0.00050$, $P>0.9$ ) and number of errors (Two-Way repeated measures ANOVA; sessions factor: $F_{3,51}=23.60,{ }^{* *} P<0.0001$; treatment factor: $F_{1,51}=7.013,{ }^{*} P<0.05$ ) were obtained for animals used in molecular studies. Overall, the results suggest that suppression of hippocampal Nurr1 impairs learning and thereby LTM by affecting accuracy (number of errors), but not latency (searching time), of task completion.

\section{Mid-training infusions}

In previous studies (Peña de Ortiz et al. 2000), we demonstrated that nurr1 mRNA is significantly up-regulated in the hippocampus during the initial and mid-acquisition stages of the holeboard spatial discrimination task. Thus, we examined the effects
B

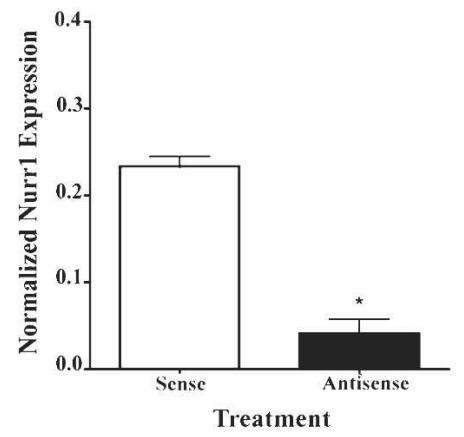

D

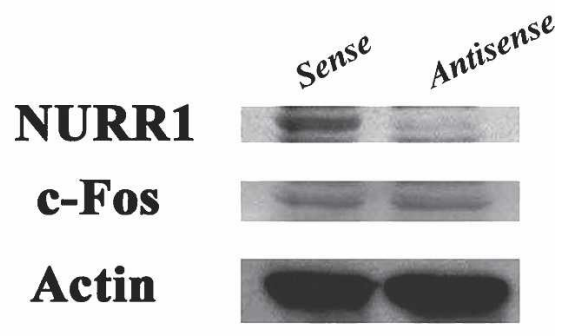

Figure 3. Results of in vivo studies addressing the effectiveness of nurr1 antisense ODN. $(A)$ Bar graphs demonstrate Nurr1 immunohistochemical analysis of pre-training ODN infused rats. Antisense ODN treatment significantly decreased the number of immunopositive nuclei in the CA3 region compared to the sense ODN-infused rats $\left({ }^{* *} P<0.01\right)$. (B) Bar graph (mean $\left.\pm S E M\right)$ depicting the injection site of rats infused with antisense ODN, compared to sense ODN-treated rats $(* P<0.05)$. (C) ern blot showing (top) Nurr1 (66 kDa), (middle) c-Fos (60 kDa), and (bottom) $\beta$-Actin (42 kDa) levels in dorsal hippocampus extracts of sense and antisense treated rats. Both $\beta$-Actin and c-Fos showed no significant differences in protein expression between the ODN antisense and sense treated rats. Results show that the antisense treatment reduced Nurr1 levels without affecting c-Fos or actin expression.

of mid-training antisense ODN infusions on the latter stages of acquisition and on retention. The behavioral results of Experiment 2 are shown in Figure 4C. Only the data obtained for animals subjected to both acquisition and retention are shown ( $N=10$ for sense group and 12 for antisense group). Two-Way repeated measures ANOVA of the errors data showed a significant effect of treatment $\left(F_{1,84}=10.24,{ }^{* *} P<0.005\right)$ and of training $\left(F_{4,84}=5.201,{ }^{* *} P<0.001\right)$. The repeated measures analysis also established a significant effect of subject matching throughout sessions $\left(F_{21,84}=2.126,{ }^{*} P<0.01\right)$. As seen in Figure $4 \mathrm{C}$, the behavioral data from sessions 1 and 2 demonstrated that untreated rats, assigned to both sense and antisense ODN groups, showed normal spatial learning as indicated by a significant decrease in the number of errors. No significant differences were detected between groups during these pre-treatment learning sessions. Multiple comparisons testing showed specific significant ODN effects for the post-treatment session $4\left({ }^{*} P<0.05\right)$, revealing that antisense treated rats committed a significantly higher number of errors during the latter stage of acquisition than controls. Compared to sense ODN-treated rats, these animals were unable to use the spatial information learned in the first two sessions and displayed a random pattern of hole visits as observed during the initial trials of session 1 . No significant difference was ob- 
served between groups, however, during the LTM test (session 5) given $7 \mathrm{~d}$ after acquisition training, although the antisense treated rats showed a tendency to commit more errors than the sense treated animals (Mean Number of Errors; antisense, $15.67 \pm 1.51$; sense, $12.82 \pm 1.46)$. Similar acquisition results as those reported above (Number of Errors, Two-Way repeated measures ANOVA; sessions factor: $F_{3,57}=7.194$, ${ }^{* * *} P<0.0005$; treatment factor: $\left.F_{1,57}=13.16,{ }^{* *} P<0.005\right)$ were obtained for animals used in molecular studies. The fact that no difference was found between the groups during the retention test could indicate that the first two sessions of training were sufficient for all animals to consolidate the mnemonic components of the task, that is, the
A

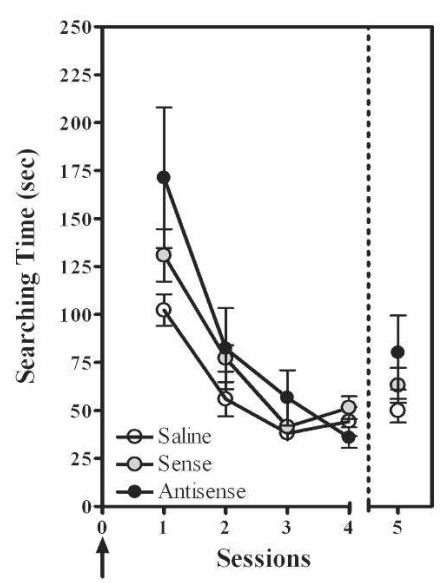

C

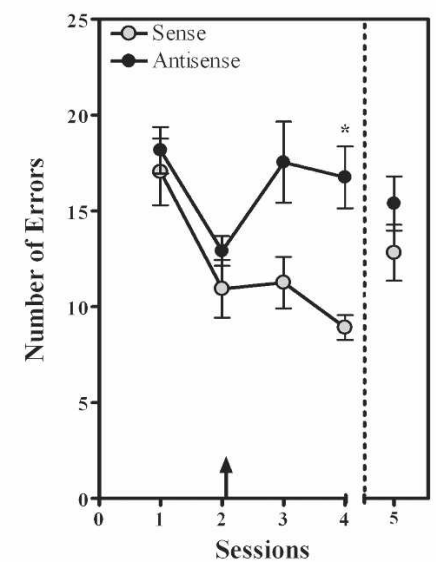

B

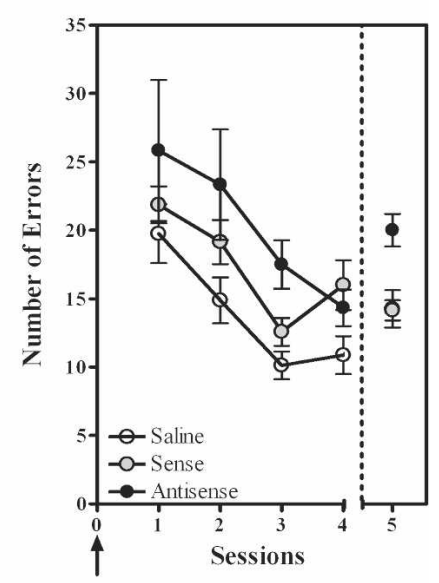

D

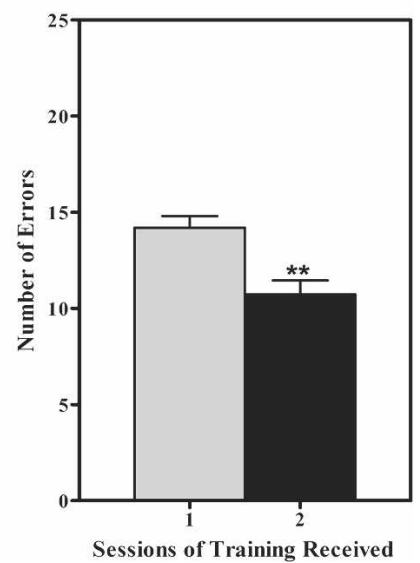

Figure 4. Pre- and mid-training microinfusions of antisense ODNs into hippocampal CA3 impair both the acquisition and LTM of spatial discrimination. Only the data for animals subjected to both acquisition and retention are shown. (A) Plot depicting the decreases in searching times during acquisition and retention for rats subjected to pre-training microinfusions of either saline, sense, or antisense ODNs. No overall difference was detected in latency to complete the task between groups throughout acquisition or retention. (B) Plot depicting the number of errors committed by rats in the three groups throughout acquisition and retention. Overall, antisense ODN-treated rats committed significantly more errors compared to sense ODN- or saline-treated animals during acquisition and retention (Two-Way ANOVA with repeated measures, ${ }^{*} P<0.05$ ), although no specific group differences were identified in particular sessions when using multiple comparison testing. (C) Behavioral analysis of rats receiving mid-training microinfusions confirms that sense and antisense ODN-treated animals displayed comparable spatial learning during sessions 1 and 2 (prior to ODN treatment). Antisense ODN-treated rats committed significantly more errors than sense ODN-treated rats at the latter stages of acquisition (Two-Way ANOVA with repeated measures, ${ }^{*} P<0.05$ ). Post hoc analysis identified specific differences between the groups during session 4 of acquisition $\left({ }^{\star} P<0.05\right)$. No significant differences between the groups were seen during the retention test. $(D)$ Bar graph depicting the results of an LTM test for intact rats subjected to one or two training sessions during acquisition. The rats that received two sessions of training committed significantly fewer errors during their retention test than the rats that received only one training session (Student $t$-test, ${ }^{*} * P<0.005$ ). Data are presented as the \pm SEM of rats trained with one (gray bar) or two (black bar) sessions. specific location of the baited holes. To test this idea, we subjected two additional groups of rats $(N=12)$, which had not been subjected to intracranial surgeries, to one or two sessions of training and compared their memory during a retention test $7 \mathrm{~d}$ after of ing two $\left(t_{22}=3.733, *<<0.005\right)$. The fact that the rats receivmean number of errors than the ones used in the ODN microinfusion studies (Fig. 4, cf. D with C) probably reflects the fact that bjected to permanent intracerebral cannulation and microinfusions. Thus, we can conclude that two sessions of training do elicit learning and memory for this task.

\section{Blocking Nurr1 expression during mid-acquisition affects future learning in the same maze}

To further assess the long-term impact of mid-training nurr1 hippocampal knockdown on spatial memory, all animals reaching the retention test in Experiment 2 were allowed to rest for $3 \mathrm{~d}$ and were then subjected to a reversal learning protocol in the same holeboard maze, but this time without ODN microinfusions (Fig. 1C). Animals were subjected to reversal learning by requiring them to acquire a new pattern of food location. Animals received four sessions of training each separated by a 1-h rest period. The retention test was given $7 \mathrm{~d}$ later. Remarkably, even in the absence of new ODN treatment, we found significant differences between the groups when analyzing the number of errors displayed by the rats during reversal training (Fig. 5A). Both groups showed learning as indicated by a significant decrease in the number of errors as the number of sessions increased (Two-Way repeated measures ANOVA; sessions factor: $\left.F_{4,68}=5.632,{ }^{* *} P<0.001\right)$. However, rats that had previously received mid-training hippocampal infusions of nurr1 antisense ODNs $(N=12)$ during their first spatial learning experience were significantly less accurate than the previously treated sense ODN controls ( $N=7$; instead of 10 , since three animals from this group were lost before completion of the reversal task) during the reversal training and retention test (TwoWay repeated measures ANOVA; treatment factor: $F_{1,68}=6.654,{ }^{*} P<0.05$ ). This group difference was also observed during the retention test for the reversal task in which the antisense treated rats showed a tendency to commit more errors than the sense treated animals (Mean Number of Errors; antisense, $11.05 \pm 1.289$; sense, $6.457 \pm 1.179$ ). It is unlikely that these differences are due 
to sensorial deficiencies in the antisense group of rats since they committed a similar number of errors as the sense treated animals during sessions 1 and 2 of the reversal training. Rather, these results suggest that suppressing the expression of Nurr1 during mid-training in the first spatial learning experience impacted future learning in the same maze.

This idea is supported by the results of comparing the search patterns used by the animals in the retention test of the reversal task to the search patterns that each animal learned during their first training experience. Figure 5B shows the perseveration index (or relative preference to use the old spatial pattern of baited holes vs. the new pattern) displayed by the animals of each group during their retention test for the reversal training task. Rats that received antisense ODN treatments during their first learning experience $(N=12)$ showed significantly higher preference for the old pattern of baited holes than the previously treated sense ODN $(N=7)$ controls $\left(t_{17}=2.446,{ }^{*} P<0.05\right)$. Overall, the data support the notion that Nurr1 suppression during mid-acquisition of the first spatial learning experience caused the animals to perseverate on the spatial information learned just prior to treatment (also see Fig. 5C).

\section{Discussion}

Mutant mice heterozygous for the nurr1 allele display increased spontaneous and amphetamine- (or stress-) induced locomotor activity (Eells et al. 2002; Backman et al. 2003), as well as deficient wheel running behavior (Werme et al. 2003). In addition, these mutant mice are predisposed to impairment in prepulse inhibition, which is thought to involve the hippocampus (for review, see Bast and Feldon 2003; Eells et al. 2006). These results support the notion raised by gene expression studies (Peña de Ortiz et al. 2000; Ressler et al. 2002; Ge et al. 2003; Al Banchaabouchi et al. 2004) that Nurr1 could be related to cognitive processes. In this study, we used an antisense knockdown approach designed to acutely and transiently disrupt hippocampal Nurr1 expression and thereby investigate the role of this immediate-early transcription factor in spatial discrimination learning and memory. Overall, the results from our behavioral studies strongly implicate hippocampal Nurr1 function in the normal processing and use of spatial information for discrimination of relevant versus irrelevant stimuli.

\section{Spatial discrimination LTM effects of Nurrl suppression in CA3}

The results suggest that when Nurr1 function in the CA3 hippocampal region is disrupted before and throughout acquisition (pre-training infusion experiments), LTM is compromised. This effect might be explained by the blockade of putative Nurr1 target genes related to the establishment of synaptic connections, such as contactin (Yoshihara et al. 1995). These LTM effects of nurr1 antisense ODNs also support previous studies on the role of the CA3 subregion in spatial memory (Steffenach et al. 2002). It has been demonstrated that the hippocampal CA3 region supports the formation of arbitrary associations because of its autoassociative network function, enabling animals to remember a particular object and its location (Rolls et al. 1989; Gilbert and Kesner 2003; Florian and Roullet 2004; Lee and Kesner 2004b). In addition, other studies demonstrated that this autoassociative network in CA3 can support a recall mechanism that is important for spatial pattern completion and that depends on $\mathrm{N}$ methyl-D-aspartate (NMDA) receptors (Nakazawa et al. 2002; Gold and Kesner 2005; Kishimoto et al. 2006). Antisense knockdown of Fos, another immediate-early transcription factor, within the rat $\mathrm{CA} 3$ region disrupted spatial memory in the radial arm maze (He et al. 2002). More importantly, a recent study by Florian et al. (2006) showed that antisense knockdown of cAMP Responsive Element Binding protein (CREB) in the CA3 region of the dorsal hippocampus impaired LTM of spatial learning in the Morris water maze. Related to this might be the fact that we have found that induction of Nurr1 expression in the CA3, but not the CA1, region following context fear conditioning is dependent on CREB function (J. Wang, S.V. Rivera-Beltrán, I. Chévere-Torres, and S. Peña de Ortiz, unpubl.). Overall, our results suggest that Nurr1 function is required in the CA3 hippocampal region for normal LTM formation, although its role in the CA1 remains to be clarified. 


\section{Suppression of Nurrl in CA3 during mid-acquisition results in an abnormal cognitive disorder}

When animals received nurr1 antisense CA3 infusions after they had received two sessions of training, they were unable to use the recently acquired information. Rather, antisense treated rats reverted to the random type of maze searching observed during the initial training trials and during habituation (when they learned that all holes in the maze were baited with food). That is, animals were incapable of using the recently acquired information and seemed to return to previously learned and consolidated spatial representations. However, when tested $7 \mathrm{~d}$ later, the antisense treated rats showed normal LTM of the spatial information acquired in sessions 1 and 2. Thus, spatial information acquired during these initial two sessions given in the absence of ODN treatment was consolidated into LTM.

The contrast between the results obtained with the pretraining and mid-training CA3 infusions of nurr 1 antisense ODNs with respect to LTM suggests a possible dual role of Nurr1 in learning and memory. According to our findings, Nurr1 expression present at the start of training or induced early during acquisition within CA3 cells is important for LTM, whereas Nurr1 expression and function during the latter stages of acquisition may be required for activating synaptic growth processes that could be important to enable future learning and memory. Indeed, we found that compared to sense ODN treatment, midtraining nurr1 antisense ODN CA3 infusions during the first spatial learning experience impaired spatial learning in the reversal task. Rats that had been treated with nurr1 antisense ODN during their first spatial learning experience displayed a higher number of errors throughout acquisition training and in the retention test of the reversal task, than sense ODN-treated animals. Under normal conditions, rats would be expected to display both spatial extinction and new spatial acquisition (Lattal and Abel 2001; Lattal et al. 2003, 2004): learning that the old spatial representation of baited holes is no longer relevant and learning that a new spatial representation is now required in order to find the food in the maze, respectively. Accordingly, sense ODN-treated rats displayed progressively decreasing tendencies to visit the holes that were baited in their first spatial learning experience as the number of sessions increased in the reversal task. However, the rats that received nurr1 antisense ODN CA3 infusions during the first spatial training showed continued preference (or perseveration) for visiting the previously baited holes. Even $7 \mathrm{~d}$ after the reversal training, the antisense group of animals showed significantly higher preference to visit the baited holes learned during the first training.

Such behavior may represent impaired spatial extinction or impaired acquisition of the new spatial representation in the maze. Since both spatial extinction and acquisition of the new spatial representation in the maze are active learning processes occurring during reversal training (Lattal and Abel 2001), we can conclude that suppression of Nurr1 expression during midacquisition of the first spatial learning experience impaired future learning in the maze. Previous studies have shown that the hippocampus may be associated to internal inhibition and perseverative responses that contribute to impairments in new learning (Kimble 1968; Whishaw and Tomie 1997). The hippocampus has also been implicated in cognitive coordination processes (Wesierska et al. 2005; Olypher et al. 2006) that allow individuals to discriminate between relevant and irrelevant stimuli and that are thought to be impaired in disorganized schizophrenia (Phillips and Silverstein 2003). Indeed, the observed cognitive inflexibility in our studies is reminiscent of behavioral symptoms, such as perseveration and cognitive disorganization (manifested as an inability to discriminate between rel- evant vs. irrelevant stimuli), in schizophrenia, manic depression, and obsessive-compulsiveness (Morice 1990; Joseph 1999; Clarke et al. 2004, 2005; Gray and Snowden 2005; Lubow and Kaplan 2005).

\section{Are perseverative responses resulting from Nurrl knockdown in CA3 related to compromised hippocampal plasticity?}

Activity-dependent plasticity allows functional, structural, and molecular adaptations in synaptic connections during development and learning (Nedivi et al. 1996; Andreasson and Kaufmann 2002; Knott et al. 2002). The nurr1 gene is necessary for the development and differentiation of dopamine precursor neurons (Castillo et al. 1998; Saucedo-Cardenas et al. 1998; Witta et al. 2000). Additional studies demonstrated that dopamine progenitor cells bearing a disrupted nurr1 gene failed to complete normal migration and the formation of synaptic connections with their normal targets in the striatum (Wallen et al. 1999). In addition, the activation of Ephrin B1 receptor by its ligand ephrin-B2 enhances nurr1 mRNA and protein levels in the midbrain, suggesting a possible role of nurr1 in axonal outgrowth (Calo et al. 2005). Previous work by Castro and colleagues (Castro et al. 2001) demonstrated that nurr1 expression in dopaminergic cell lines can induce the extension of neurites. Interestingly, the gene encoding neurotrophin 3 (NT-3) is among the candidate genes containing NBRE elements in their 5'-promoter upstream region. Neurotrophins in general, and NT-3 in particular, have been associated with sprouting, axonal growth, synaptic plasticity, and learning (Kang and Schuman 1996; Kaisho et al. 1999; Schwyzer et al. 2002; Xu et al. 2002; Mizuno et al. 2003). Hence, one possible role of Nurr1 during learning is the activation of cellular machineries necessary to promote synaptic connectivity and plasticity, which are also relevant during development. Spatial learning has been shown to induce increased numbers of mossy fiber terminals (synaptogenesis) in the dorsal hippocampal CA3 region (Ramirez-Amaya et al. 1999, 2001). Thus, suppression of Nurr1 expression in hippocampal CA3 cells during midacquisition of the first spatial learning experience may have prevented the formation of new synaptic terminals, which could be available for establishing future synaptic connections during future learning experiences. Disrupting the normal balance between the stable fixation of memory representations via the establishment of strong synaptic connections and the generation of new potential pre-synaptic and post-synaptic sites for use in future learning experiences could explain the perseverative responses caused by Nurr1 suppression in our experiments, and at least part of the cognitive symptoms in schizophrenia. In fact, a recent study found reduced mossy fiber-CA3 synapses in postmortem tissue of schizophrenic patients (Kolomeets et al. 2005). Taken together, these results support the hypothesis that Nurr1 is important for hippocampal-dependent cognitive processes that may be impaired in patients suffering from neuropsychiatric conditions such as schizophrenia.

\section{Materials and Methods}

\section{Subjects}

Male Long Evans rats weighing between 275 and 300 g (Harlan Sprague Dawley) were used in our studies. Upon arrival, rats were taken to the behavioral testing room and placed in home cages in pairs. Food and water were available at all times except when the rats entered the food restriction protocol, in which they were maintained at $85 \%$ of free feeding weight in preparation for the holeboard spatial discrimination training. The rats were kept on a 12-h light/12-h dark cycle (lights on at 6:00 a.m.). All procedures were conducted in agreement with the National Institutes 
of Health Guide for care and use of laboratory animals and were approved by the Institutional Animal Care and Use Committee.

\section{Antisense ODNs and microinfusion procedure}

Fully phosphorothioate-modified ODNs were synthesized and purified by Biognostik. All three batches of ODNs used to complete these studies were received as sterile phosphorothioate DNA-Na salts, lyophilized, deprotected, and fully purified by high performance liquid chromatography. The sequence design of the 21-bp nurr1 antisense ODN was 5'-CATGGCTTCAGCCG AGTGATT-3'; and sense ODN was 5'-AATCACTCGGCTGA AGCCATG-3'; these sequences correspond to nucleotides 25-45 of rat nurr1 (hzf-3) mRNA (Peña de Ortiz and Jamieson Jr. 1996). The nurr 1 antisense ODN was designed to target the start codon of rat nurr1 mRNA. Phosphorothioated ODNs were used because this modification has shown resistance to nuclease degradation (Agrawal 1999). In addition, the antisense sequence was designed taking into consideration factors such as length of the oligomer, base composition, and specificity for the nurr1 mRNA. In addition, FITC-labeled nurr1 antisense ODNs were used for diffusion studies. The complementary sense or reverse ODN and vehicle (saline) were used as controls. BLAST searches of the above sequences were performed on the National Center for Biotechnology Information BLAST server using the GenBank database (McGinnis and Madden 2004). ODNs were dissolved in sterile $0.9 \%$ saline solution with a final concentration of $16.8 \mu \mathrm{g} / \mu \mathrm{L}$ ( $2 \mathrm{nmol})$, a concentration used previously with antisense ODN delivered intracerebrally to inhibit protein expression in vivo (Lamprecht et al. 1997).

\section{Plasmids}

The pCI-Nurr1 encoding full-length mouse nurr1 as well as the luciferase reporter construct NBRE3x (pGL2 plasmid containing three canonical NBREs) (Woronicz et al. 1995) were generously provided by Michael J. Bannon (Wayne State Univ. School of Medicine, Detroit, MI) (Sacchetti et al. 2001). Also, Carlos González (Univ. of Puerto Rico, San Juan, PR) kindly provided the pRL-CMV encoding the Renilla luciferase control reporter.

\section{Cell culture and transfections}

Transient transfection studies were performed in embryonic human $\mathrm{AD} 293$ kidney cell lines, grown at $37^{\circ} \mathrm{C}$ in a $5 \% \mathrm{CO}_{2}$ humidified atmosphere in Dulbecco's modified Eagle's medium high glucose (Invitrogen) containing 10\% heat-inactivated fetal bovine serum (GIBCO). Cells were plated in six-well plates $\left(5 \times 10^{5}\right.$ cells/well $) 24 \mathrm{~h}$ before transfection. Typically, cells were cotransfected with $3 \mu \mathrm{g}$ of the reporter construct and $3 \mu \mathrm{g}$ of expression vectors, each complexed at a ratio of $1 \mu \mathrm{g}$ DNA/3 $\mu \mathrm{L}$ of liposome reagent (FuGene 6; Roche Applied Science), following the instructions of the manufacturer. The plasmid pRL-CMV Renilla was also included in the cotransfection (1:10 of total pCINurr1) in all experiments as an internal control for normalization of transfection efficiency. After $24 \mathrm{~h}$ of incubation, the lipid/ DNA mix was replaced with fresh medium before ODN treatment. Before treatment, ODNs were dissolved in ultrapure water with a final concentration of $8.4 \mu \mathrm{g} / \mu \mathrm{L}(1 \mathrm{nmol})$, half of the dose used in in vivo studies. One microliter of ODN solution was incubated with FuGene 6 (Roche) in Dulbecco's modified Eagle's medium (without serum) for $30 \mathrm{~min}$ at room temperature and was then added to the cells and incubated for $24 \mathrm{~h}$ at $37^{\circ} \mathrm{C}$. Approximately $24 \mathrm{~h}$ after ODN treatment, cell extracts were analyzed for luciferase and Renilla activities using the DualLuciferase Reporter Assay System (Promega) and a Luminometer (TD20/20 Luminometer; Turner Designs).

\section{Surgery}

Animals were kept in the Animal House Facilities of the Department of Biology at the University of Puerto Rico and were handled immediately upon arrival for several days in order to minimize stress before the surgery procedure. The handling and surgical procedures used were similar to those reported previously by us (Vázquez and Peña de Ortiz 2004). On the day of surgery, rats were first injected with atropine (s.c. $0.54 \mathrm{mg} / \mathrm{kg}$ ) and were then anesthetized with $2.5 \%$ sodium pentobarbital at an intraperitoneal dose of $50 \mathrm{mg} / \mathrm{kg}$. Standard stereotaxic procedures were used to implant bilateral indwelling guide cannulae aimed at the hippocampus using coordinates based on the Paxinos and Watson rat atlas (Paxinos and Watson 1998). The coordinates for the hippocampal CA3 cannulations were as follows: anterior-posterior (AP), $-3.3 \mathrm{~mm}$ from bregma; medio-lateral (ML), $\pm 2.7 \mathrm{~mm}$ from midline; dorso-ventral (DV), $-2.7 \mathrm{~mm}$ from skull. The cannulae ( $8 \mathrm{~mm}$ long) were secured to stainless steel screws with dental cement and light-curable resin. Wire stylets were inserted in the guides and checked every day to ensure clean and functional cannulae. After surgery, animals were allowed to recover for $4 \mathrm{~d}$ before behavioral experiments.

\section{Diffusion experiments}

After cannulae implantation, injector cannulae were inserted, and a group of animals were microinfused with FITC-nurr1 antisense ODNs to estimate the area of ODN diffusion within the hippocampus. An infusion of $1 \mu \mathrm{L}$ of FITC-nurr1 antisense ODNs was delivered bilaterally into the dorsal hippocampi. Animals were sacrificed at the following time points: $1,3,6$, and $24 \mathrm{~h}$ $(N=2$ for each time point). All animals were anesthetized and decapitated, and the brains were isolated and stored at $-80^{\circ} \mathrm{C}$. Coronal hippocampal sections $20 \mu \mathrm{m}$ thick were visualized using a fluorescence microscope (Pixcell II; Arcturus), and digitized pictures were obtained.

\section{Food restriction and habituation}

Following the recovery period from surgery, rats entered a foodrestriction and habituation period to prepare them for training in the holeboard spatial discrimination maze apparatus, as described before by us (Peña de Ortiz et al. 2000; Vázquez et al. 2000; Robles et al. 2003; Vázquez and Peña de Ortiz 2004). Rats received two habituation trials (in the same day), each separated by a $1-h$ rest period. The habituation trials were as those described by us previously (Peña de Ortiz et al. 2000).

\section{Intrahippocampal microinfusions}

In order to ensure the effectiveness of the infusion pump system and to get the animals adapted to receiving intracerebral microinfusions, we subjected each animal to bilateral infusions ( 2 min at $0.5 \mu \mathrm{L} / \mathrm{min}$ ) of $0.9 \%$ saline prior to the first habituation trial (see above). The infusion was accomplished by inserting a 30gauge stainless steel injector into the guide cannulae so that they extended $1.0 \mathrm{~mm}$ beyond the tip of the guide right above the CA3 pyramidal neurons of the hippocampus. Previous to spatial training, rats were randomly distributed into three groups that received saline, antisense, or sense ODN infusions. In the training day, rats were microinjected with a single infusion of the ODNs or saline $1 \mathrm{~h}$ prior to sessions 1 (pre-training infusions) or 3 (mid-training infusions) of spatial training. After removing the stylets, bilateral intracerebral microinfusions were given with the injection needle connected to a $10-\mu \mathrm{L}$ Hamilton syringe by polyethylene tubing. ODNs or vehicle were administered with an infusion time of 2 min followed by a 1-min diffusion time using a microdrive pump (Harvard Apparatus). An infusion of $1 \mu \mathrm{L}$ of ODN ( $2 \mathrm{nmol})$ was delivered into each side of the hippocampus. After ODN or vehicle infusions, the injectors were removed, the stylets were replaced, and the animals were returned to their home cages. All injections were done using a blind experimental design.

\section{Spatial discrimination learning}

Spatial training began the day after habituation and was done following similar protocols as those reported previously (Peña de Ortiz et al. 2000; Vázquez et al. 2000; Robles et al. 2003; Vázquez and Peña de Ortiz 2004; Álvarez-Jaimes et al. 2004). During the acquisition phase of spatial learning, animals received four sessions of training (each consisting of five trials lasting a maximum of $5 \mathrm{~min}$ ) and each separated by a 1 -h rest period. The behavioral 
parameters recorded in each trial were the following: (1) the total time to complete each trial measured by time watches, (2) the number of errors (visits to empty holes and repeat visits to baited holes), and (3) the search strategy (pattern of search behavior). After acquisition training, animals rested for $7 \mathrm{~d}$ without any further training, but were maintained in the food-restriction protocol. The rats then received a retention test, which consisted of five training trials each lasting a maximum of $5 \mathrm{~min}$. Food pellets were placed in the same locations in which they were during acquisition training.

\section{Reversal training}

For the mid-training infusion experiments, antisense and sense spatially trained animals rested for $3 \mathrm{~d}$ after their retention test without any further training, but the food-restriction protocol was maintained. Animals were then subjected to a new spatial acquisition protocol in the holeboard maze without any ODN or vehicle microinfusions. For the reversal training, a new pattern of food location was used for each animal. After acquisition training in the reversal task, animals were allowed to rest, while continuing in the food-restriction protocol. The retention test was given $7 \mathrm{~d}$ after the reversal training. The searching trajectory, number of errors, and time needed to complete the task were recorded for each trial. The perseveration index for the retention test, consisting of five trials (see above), was calculated using the following formula: Perseveration Index $=[(5$ trials $)-$ (number of trials in which animals used the new pattern of baited holes) $] \div[$ (number of trials in which animals used the new pattern baited holes) + (number of trials in which animals used the old pattern of baited holes)].

\section{Histological analyses}

In order to verify cannula/injector positions for animals used in behavioral studies, rats were decapitated immediately after the end of the retention test. Brains were dissected, washed with phosphate buffer saline (PBS), placed on dry ice, and stored at $-80^{\circ} \mathrm{C}$. Fresh frozen coronal sections were mounted on gelatincoated slides and fixed with $2 \%$ paraformaldehyde for $20 \mathrm{~min}$ and washed twice with PBS $1 \times, 5 \mathrm{~min}$ each time. The sections were defatted by washing in chloroform for $5 \mathrm{~min}$ and then stained with $0.1 \%$ thionin (Nissl stain) dissolved in ultrapure water. A light binocular microscope was used for corroboration of cannula/injector placements, and infusion sites were confirmed visually (see Results). Only the data obtained from animals showing correct cannula placements were used for our analyses of the effects of ODN treatment.

\section{Immunohistochemistry}

A group of animals that had received pre-training CA3 ODN infusions was sacrificed immediately after the end of session 4 of training. Brains were dissected, washed with phosphate buffer saline, placed on dry ice, and stored at $-80^{\circ} \mathrm{C}$. Fresh frozen alternate coronal sections ( $20 \mu \mathrm{m}$ thick) were obtained in a cryostat at $-20^{\circ} \mathrm{C}$, placed on positively charged glass slides, and stored at $-80^{\circ} \mathrm{C}$. The sections were then used for Nurr1 immunohistochemistry as described previously (Ge et al. 2003; Al Banchaabouchi et al. 2004). Diaminobenzidine (DAB)-oxidized brown precipitates were visualized with a binocular light microscope (Olympus BX40 microscope), and photomicrographs were taken with a Polaroid DMC digital camera $(1600 \times 1200$ dpi $)$ with $10 \times$ objective magnification. Nurr1-immunopositive nuclei were counted within the CA3 and dentate gyrus hippocampal subregion around the microinfused area using the Image J program (http://rsb.info.nih.gov/ij) as described by us previously (Ge et al. 2003; Al Banchaabouchi et al. 2004; Vázquez and Peña de Ortiz 2004). A total of six slides (each containing three to four serial sections) per animal ( 24 serial coronal sections for each animal) were used for the counting of Nurr1-immunopositive nuclei of the dorsal hippocampus. The analyzed portion of dorsal hippocampus represents the area at and the area surrounding (anteriorly and posteriorly) the site of microinfusions. Image J counting was done by a technician who was blind in terms of which sections corresponded to treated or control animals.

\section{Nuclear protein extraction and Western blotting}

Tissue from the dorsal hippocampus or the hippocampal CA3 was collected in pools of three rats per condition. The procedures for nuclear protein extraction (performed at $4^{\circ} \mathrm{C}$ ) were modified from Best et al. (1999) and were similar to those previously used by us (Ge et al. 2003; Al Banchaabouchi et al. 2004; Santini et al. 2004). Protein samples were stored at $-80^{\circ} \mathrm{C}$ until used. Western blotting was performed as described previously (Ge et al. 2003; Al Banchaabouchi et al. 2004). The blotted membrane was incubated first with 1:500 Nurr1 antibody (Santa Cruz Biotechnology) and subsequently with 1:5000 anti-rabbit horseradish peroxidase conjugated secondary antibody (Cell Signaling Technology, Inc.). Antibody binding specificity was confirmed by immunoabsorption with a Nurr1 peptide. The ECL Western blotting system (Amersham Biosciences) was used for immune detection. Membranes were then stripped of antibodies and re-probed for Fos (1:200 c-Fos antibody) (see Santini et al. 2004 for detailed conditions) and later for $\beta$-actin as described previously (Ge et al. 2003; Al Banchaabouchi et al. 2004). Films were scanned and analyzed in a densitometer (Molecular Dynamics). Expression was normalized by dividing the mean Nurr1 or Fos optical densities per condition by the corresponding $\beta$-actin optical densities.

\section{Statistical analysis}

Prism 4 software (GraphPad Software) was used to carry out statistical analysis on all the behavioral and biochemical data. For all experiments, we assumed statistical significance at $P<0.05$. Two-Way repeated measures ANOVA was used for comparing performance of rats treated with the vehicle, antisense, or sense ODNs for each learning measure during acquisition and retention tests (searching time and number of errors). Bonferroni posteriori tests were performed when significance was reached $(P<0.05)$ in the ANOVAs. Finally, the Student's $t$-test was used to determine the statistical significance of the retention test data for rats trained with one versus two sessions, of the effect of sense versus antisense ODN treatments on the perseveration index during the retention test of the reversal training, and in all the biochemical studies.

\section{Acknowledgments}

This work was supported by the NIH (SPO grants NIGMS-MBRS SOGGMO 8102-26S1, NINDS-SNRP U54-NS39405 and IDEACOBRE: NCRR-NIH 5P20 RR 15565-02; CSMV grant 1 R29 DA11665-05; NIMH-APA Diversity Program in Neuroscience Fellowship to W.I.C.-C.; 5 T32 MH18882-15, 16, 17; NIGMS-MBRSRISE fellowship to L.P. and NC 5R25GM061151). We thank Edwin J. Barea-Rodríguez and José E. García-Arrarás for helpful comments on this manuscript. We also express our gratitude to Michael J. Bannon for generously providing the pCI-Nurr1 and luciferase NBRE3x reporter constructs used in our in vitro studies. We thank Carlos González for sharing the pRL-CMV encoding Renilla luciferase control reporter construct and luminometer also used in the in vitro studies.

\section{References}

Agrawal, S. 1999. Importance of nucleotide sequence and chemical modifications of antisense oligonucleotides. Biochim. Biophys. Acta 1489: $53-68$.

Al Banchaabouchi, M., Peña de Ortiz, S., Menendez, R., Ren, K., and Maldonado-Vlaar, C.S. 2004. Chronic lithium decreases Nurr1 expression in the rat brain and impairs spatial discrimination. Pharmacol. Biochem. Behav. 79: 607-621.

Álvarez-Jaimes, L., Betancourt, E., Centeno-Gonzalez, M., Feliciano-Rivera, M.Z., Rodriguez, D., Peña de Ortiz, S., and Maldonado-Vlaar, C.S. 2004. Spatial learning in rats is impaired by microinfusions of protein kinase $\mathrm{C}-\gamma$ antisense oligodeoxynucleotide within the nucleus accumbens. Neurobiol. Learn. Mem. 81: 120-136. Andreasson, K.I. and Kaufmann, W.E. 2002. Role of immediate early 
gene expression in cortical morphogenesis and plasticity. Results Probl. Cell Differ. 39: 113-137.

Antonova, E., Sharma, T., Morris, R., and Kumari, V. 2004. The relationship between brain structure and neurocognition in schizophrenia: A selective review. Schizophr. Res. 70: 117-145.

Backman, C., You, Z.B., Perlmann, T., and Hoffer, B.J. 2003. Elevated locomotor activity without altered striatal dopamine contents in Nurr1 heterozygous mice after acute exposure to methamphetamine. Behav. Brain Res. 143: 95-100.

Bannon, M.J., Pruetz, B., Manning-Bog, A.B., Whitty, C.J., Michelhaugh, S.K., Sacchetti, P., Granneman, J.G., Mash, D.C., and Schmidt, C.J. 2002. Decreased expression of the transcription factor NURR1 in dopamine neurons of cocaine abusers. Proc. Natl. Acad. Sci. 99: 6382-6385.

Bast, T. and Feldon, J. 2003. Hippocampal modulation of sensorimotor processes. Prog. Neurobiol. 70: $319-345$

Best, J.D., Maywood, E.S., Smith, K.L., and Hastings, M.H. 1999. Rapid resetting of the mammalian circadian clock. J. Neurosci. 19: 828-835.

Buervenich, S., Carmine, A., Arvidsson, M., Xiang, F., Zhang, Z., Sydow, O., Jonsson, E.G., Sedvall, G.C., Leonard, S., Ross, R.G., et al. 2000. NURR1 mutations in cases of schizophrenia and manic-depressive disorder. Am. J. Med. Genet. 96: 808-813.

Calo, L., Spillantini, M., Nicoletti, F., and Allen, N.D. 2005. Nurr1 co-localizes with EphB1 receptors in the developing ventral midbrain, and its expression is enhanced by the EphB1 ligand, ephrinB2. J. Neurochem. 92: 235-245.

Carmine, A., Buervenich, S., Galter, D., Jonsson, E.G., Sedvall, G.C., Farde, L., Gustavsson, J.P., Bergman, H., Chowdari, K.V. Nimgaonkar, V.L., et al. 2003. NURR1 promoter polymorphisms: Parkinson's disease, schizophrenia, and personality traits. Am. J. Med. Genet. B Neuropsychiatr. Genet. 120: $51-57$.

Castillo, S.O., Baffi, J.S., Palkovits, M., Goldstein, D.S., Kopin, I.J., Witta, J., Magnuson, M.A., and Nikodem, V.M. 1998. Dopamine biosynthesis is selectively abolished in substantia nigra/ventral tegmental area but not in hypothalamic neurons in mice with targeted disruption of the Nurr1 gene. Mol. Cell. Neurosci. 11: 36-46.

Castro, D.S., Hermanson, E., Joseph, B., Wallen, A., Aarnisalo, P., Heller, A., and Perlmann, T. 2001. Induction of cell cycle arrest and morphological differentiation by Nurr1 and retinoids in dopamine MN9D cells. J. Biol. Chem. 276: 43277-43284.

Chen, Y.H., Tsai, M.T., Shaw, C.K., and Chen, C.H. 2001. Mutation analysis of the human NR4A2 gene, an essential gene for midbrain dopaminergic neurogenesis, in schizophrenic patients. Am. J. Med. Genet. 105: 753-757.

Cheng, L.E.-C., Chan, F.K.-M., Cado, D., and Winoto, A. 1997. Functional redundancy of the Nur77 and Nor-1 orphan steroid receptors in T-cell apoptosis. EMBO J. 16: 1865-1875.

Chu, Y., Le, W., Kompoliti, K., Jankovic, J., Mufson, E.J., and Kordower, J.H. 2006. Nurr1 in Parkinson's disease and related disorders. J. Comp. Neurol. 494: 495-514.

Clarke, H.F., Dalley, J.W., Crofts, H.S., Robbins, T.W., and Roberts, A.C. 2004. Cognitive inflexibility after prefrontal serotonin depletion. Science 304: 878-880.

Clarke, H.F., Walker, S.C., Crofts, H.S., Dalley, J.W., Robbins, T.W., and Roberts, A.C. 2005. Prefrontal serotonin depletion affects reversal learning but not attentional set shifting. J. Neurosci. 25: 532-538.

Daumas, S., Halley, H., Frances, B., and Lassalle, J.M. 2005. Encoding, consolidation, and retrieval of contextual memory: Differential involvement of dorsal CA3 and CA1 hippocampal subregions. Learn. Mem. 12: 375-382.

Eells, J.B. 2003. The control of dopamine neuron development, function and survival: Insights from transgenic mice and the relevance to human disease. Curr. Med. Chem. 10: 857-870.

Eells, J.B., Lipska, B.K., Yeung, S.K., Misler, J.A., and Nikodem, V.M. 2002. Nurr1-null heterozygous mice have reduced mesolimbic and mesocortical dopamine levels and increased stress-induced locomotor activity. Behav. Brain Res. 136: 267-275.

Eells, J.B., Misler, J.A., and Nikodem, V.M. 2006. Early postnatal isolation reduces dopamine levels, elevates dopamine turnover and specifically disrupts prepulse inhibition in Nurr1-null heterozygous mice. Neuroscience 140: $1117-1126$.

Feng, J., Chen, J., Yan, J., Jones, I.R., Craddock, N., Cook Jr., E.H., Goldman, D., Heston, L.L., and Sommer, S.S. 2005. Structural variants in the retinoid receptor genes in patients with schizophrenia and other psychiatric diseases. Am. J. Med. Genet. B Neuropsychiatr. Genet. 133: 50-53.

Florian, C. and Roullet, P. 2004. Hippocampal CA3-region is crucial for acquisition and memory consolidation in Morris water maze task in mice. Behav. Brain Res. 154: 365-374.

Florian, C., Mons, N., and Roullet, P. 2006. CREB antisense oligodeoxynucleotide administration into the dorsal hippocampa CA3 region impairs long- but not short-term spatial memory in mice. Learn. Mem. 13: 465-472.

Ge, H., Chiesa, R., and Peña de Ortiz, S. 2003. Hzf-3 expression in the amygdala after establishment of conditioned taste aversion. Neuroscience 120: $1-4$

Gilbert, P.E. and Kesner, R.P. 2003. Localization of function within the dorsal hippocampus: The role of the CA3 subregion in paired-associate learning. Behav. Neurosci. 117: 1385-1394.

Gold, A.E. and Kesner, R.P. 2005. The role of the CA3 subregion of the dorsal hippocampus in spatial pattern completion in the rat. Hippocampus 15: 808-814.

Gray, N.S. and Snowden, R.J. 2005. The relevance of irrelevance to schizophrenia. Neurosci. Biobehav. Rev. 29: 989-999.

Harvey, P.D., Bowie, C.R., and Friedman, J.I. 2001. Cognition in schizophrenia. Curr. Psychiatry Rep. 3: 423-428.

He, J., Yamada, K., and Nabeshima, T. 2002. A role of Fos expression in the CA3 region of the hippocampus in spatial memory formation in rats. Neuropsychopharmacology 26: 259-268.

Honkaniemi, J. and Sharp, F.R. 1999. Prolonged expression of zinc finger immediate-early gene mRNAs and decreased protein synthesis following kainic acid induced seizures. Eur. J. Neurosci. 11: 10-17.

Iwayama-Shigeno, Y., Yamada, K., Toyota, T., Shimizu, H., Hattori, E., Yoshitsugu, K., Fujisawa, T., Yoshida, Y., Kobayashi, T., Toru, M., et al. 2003. Distribution of haplotypes derived from three common variants of the NR4A2 gene in Japanese patients with schizophrenia. Am. J. Med. Genet. B Neuropsychiatr. Genet. 118: 20-24.

Jankovic, J., Chen, S., and Le, W.D. 2005. The role of Nurr1 in the development of dopaminergic neurons and Parkinson's disease. Prog. Neurobiol. 77: 128-138.

Johnson, J.D. 2005. Dysfunction of the anterior hippocampus: The cause of fundamental schizophrenic symptoms? Med. Hypotheses 65: $55-60$.

Joseph, R. 1999. Frontal lobe psychopathology: Mania, depression, confabulation, catatonia, perseveration, obsessive compulsions, and schizophrenia. Psychiatry 62: 138-172.

Kaisho, Y., Ohta, H., Miyamoto, M., and Igarashi, K. 1999. Nerve growth factor promoter driven neurotrophin-3 overexpression in the mouse and the protective effect of transgene on age-related behavioral deficits. Neurosci. Lett. 277: 181-184.

Kang, H. and Schuman, E.M. 1996. A requirement for local protein synthesis in neurotrophin-induced hippocampal synaptic plasticity. Science 273: 1402-1406.

Kimble, D.P. 1968. Hippocampus and internal inhibition. Psychol. Bull. 70: $285-295$.

Kishimoto, Y., Nakazawa, K., Tonegawa, S., Kirino, Y., and Kano, M. 2006. Hippocampal CA3 NMDA receptors are crucial for adaptive timing of trace eyeblink conditioned response. J. Neurosci. 26: $1562-1570$

Knott, G.W., Quairiaux, C., Genoud, C., and Welker, E. 2002. Formation of dendritic spines with GABAergic synapses induced by whisker stimulation in adult mice. Neuron 34: 265-273.

Kolomeets, N.S., Orlovskaya, D.D., Rachmanova, V.I., and Uranova, N.A. 2005. Ultrastructural alterations in hippocampal mossy fiber synapses in schizophrenia: A postmortem morphometric study. Synapse 57: 47-55.

Lamprecht, R., Hazvi, S., and Dudai, Y. 1997. cAMP response element-binding protein in the amygdala is required for long- but not short-term conditioned taste aversion memory. J. Neurosci. 17: $8443-8450$

Lattal, K.M. and Abel, T. 2001. Different requirements for protein synthesis in acquisition and extinction of spatial preferences and context-evoked fear. J. Neurosci. 21: $5773-5780$.

Lattal, K.M., Mullen, M.T., and Abel, T. 2003. Extinction, renewal, and spontaneous recovery of a spatial preference in the water maze. Behav. Neurosci. 117: 1017-1028.

Lattal, K.M., Honarvar, S., and Abel, T. 2004. Effects of post-session injections of anisomycin on the extinction of a spatial preference and on the acquisition of a spatial reversal preference. Behav. Brain Res. 153: 327-339.

Law, S.W., Conneely, O.M., DeMayo, F.J., and O'Malley, B.W. 1992. Identification of a new brain-specific transcription factor, NURR1 Mol. Endocrinol. 6: 2129-2135.

Lee, I. and Kesner, R.P. 2004a. Differential contributions of dorsal hippocampal subregions to memory acquisition and retrieval in contextual fear-conditioning. Hippocampus 14: 301-310.

Lee, I. and Kesner, R.P. 2004b. Encoding versus retrieval of spatial memory: Double dissociation between the dentate gyrus and the perforant path inputs into CA3 in the dorsal hippocampus. Hippocampus 14: 66-76.

Lee, I., Jerman, T.S., and Kesner, R.P. 2005. Disruption of delayed memory for a sequence of spatial locations following CA1- or CA3-lesions of the dorsal hippocampus. Neurobiol. Learn. Mem. 84: $138-147$. 
Lubow, R.E. and Kaplan, O. 2005. The visual search analogue of latent inhibition: Implications for theories of irrelevant stimulus processing in normal and schizophrenic groups. Psychon. Bull. Rev. 12: 224-243.

McGinnis, S. and Madden, T.L. 2004. BLAST: At the core of a powerful and diverse set of sequence analysis tools. Nucleic Acids Res. 32: W20-W25.

Mizuno, M., Yamada, K., He, J., Nakajima, A., and Nabeshima, T. 2003. Involvement of BDNF receptor TrkB in spatial memory formation. Learn. Mem. 10: 108-115.

Morice, R. 1990. Cognitive inflexibility and pre-frontal dysfunction in schizophrenia and mania. Br. J. Psychiatry 157: 50-54.

Nakazawa, K., Quirk, M.C., Chitwood, R.A., Watanabe, M., Yeckel, M.F., Sun, L.D., Kato, A., Carr, C.A., Johnston, D., Wilson, M.A., et al. 2002. Requirement for hippocampal CA3 NMDA receptors in associative memory recall. Science 297: 211-218.

Nedivi, E., Fieldust, S., Theill, L.E., and Hevron, D. 1996. A set of genes expressed in response to light in the adult cerebral cortex and regulated during development. Proc. Natl. Acad. Sci. 93: 2048-2053.

Oades, R.D. 1981. Impairments of search behaviour in rats after haloperidol treatment, hippocampal or neocortical damage suggest a mesocorticolimbic role in cognition. Biol. Psychol. 12: 77-85.

Oades, R.D. and Isaacson, R.L. 1978. The development of food search behavior by rats: The effects of hippocampal damage and haloperidol. Behav. Biol. 24: 327-337.

Olypher, A.V., Klement, D., and Fenton, A.A. 2006. Cognitive disorganization in hippocampus: A physiological model of the disorganization in psychosis. J. Neurosci. 26: 158-168.

Paxinos, G. and Watson, C. 1998. The rat brain in stereotaxic coordinates, 4th ed. Academic Press, New York.

Peña de Ortiz, S. and Jamieson Jr., G.A. 1996. HZF-3, an immediate-early orphan receptor homologous to NURR1/NOT: Induction upon membrane depolarization and seizures. Brain Res. Mol. Brain Res. 38: $1-13$.

Peña de Ortiz, S., Maldonado-Vlaar, C.S., and Carrasquillo, Y. 2000 Hippocampal expression of the orphan nuclear receptor gene hzf-3/nurr1 during spatial discrimination learning. Neurobiol. Learn. Mem. 74: 161-178.

Phillips, W.A. and Silverstein, S.M. 2003. Convergence of biological and psychological perspectives on cognitive coordination in schizophrenia. Behav. Brain Sci. 26: 65-82.

Ramirez-Amaya, V., Escobar, M.L., Chao, V., and Bermudez-Rattoni, F. 1999. Synaptogenesis of mossy fibers induced by spatial water maze overtraining. Hippocampus 9: 631-636.

Ramirez-Amaya, V., Balderas, I., Sandoval, J., Escobar, M.L., and Bermudez-Rattoni, F. 2001. Spatial long-term memory is related to mossy fiber synaptogenesis. J. Neurosci. 21: 7340-7348.

Ressler, K.J., Paschall, G., Zhou, X.L., and Davis, M. 2002. Regulation of synaptic plasticity genes during consolidation of fear conditioning. $J$. Neurosci. 22: 7892-7902.

Robles, Y., Vivas-Mejia, P.E., Ortiz-Zuazaga, H.G., Felix, J., Ramos, X., and Peña de Ortiz, S. 2003. Hippocampal gene expression profiling in spatial discrimination learning. Neurobiol. Learn. Mem. 80: 80-95.

Rolls, E.T., Miyashita, Y., Cahusac, P.M., Kesner, R.P., Niki, H., Feigenbaum, J.D., and Bach, L. 1989. Hippocampal neurons in the monkey with activity related to the place in which a stimulus is shown. J. Neurosci. 9: 1835-1845.

Ruano, D., Macedo, A., Dourado, A., Soares, M.J., Valente, J., Coelho, I., Santos, V., Azevedo, M.H., Goodman, A., Hutz, M.H., et al. 2004. NR4A2 and schizophrenia: Lack of association in a Portuguese/Brazilian study. Am. J. Med. Genet. B Neuropsychiatr. Genet. 128: 41-45.

Sacchetti, P., Mitchell, T.R., Granneman, J.G., and Bannon, M.J. 2001. Nurr1 enhances transcription of the human dopamine transporter gene through a novel mechanism. J. Neurochem. 76: 1565-1572.

Santini, E., Ge, H., Ren, K., Peña de Ortiz, S., and Quirk, G.J. 2004 Consolidation of fear extinction requires protein synthesis in the medial prefrontal cortex. J. Neurosci. 24: 5704-5710.

Saucedo-Cardenas, O., Quintana-Hau, J.D., Le, W.D., Smidt, M.P., Cox, J.J., De Mayo, F., Burbach, J.P., and Conneely, O.M. 1998. Nurr1 is essential for the induction of the dopaminergic phenotype and the survival of ventral mesencephalic late dopaminergic precursor neurons. Proc. Natl. Acad. Sci. 95: 4013-4018.

Schwyzer, L., Mateos, J.M., Abegg, M., Rietschin, L., Heeb, L., Thompson, S.M., Luthi, A., Gahwiler, B.H., and McKinney, R.A 2002. Physiological and morphological plasticity induced by chronic treatment with NT-3 or NT-4/5 in hippocampal slice cultures. Eur. J. Neurosci. 16: 1939-1948.
Steffenach, H.A., Sloviter, R.S., Moser, E.I., and Moser, M.B. 2002. Impaired retention of spatial memory after transection of longitudinally oriented axons of hippocampal CA3 pyramidal cells. Proc. Natl. Acad. Sci. 99: 3194-3198.

Stubley-Weatherly, L., Harding, J.W., and Wright, J.W. 1996. Effects of discrete kainic acid-induced hippocampal lesions on spatial and contextual learning and memory in rats. Brain Res. 716: 29-38.

Sweatt, J.D. 2004. Hippocampal function in cognition. Psychopharmacology 174: 99-110.

Van den Buuse, M., Garner, B., and Koch, M. 2003. Neurodevelopmental animal models of schizophrenia: Effects on prepulse inhibition. Curr. Mol. Med. 3: 459-471.

Vázquez, A. and Peña de Ortiz, S. 2004. Lead $\left(\mathrm{Pb}^{+2}\right)$ impairs long-term memory and blocks learning-induced increases in hippocampal protein kinase C activity. Toxicol. Appl. Pharmacol. 200: 27-39.

Vázquez, S.I., Vázquez, A., and Peña de Ortiz, S. 2000. Different hippocampal activity profiles for PKA and PKC in spatial discrimination learning. Behav. Neurosci. 114: 1109-1118.

Wallen, A., Zetterstrom, R.H., Solomin, L., Arvidsson, M., Olson, L., and Perlmann, T. 1999. Fate of mesencephalic AHD2-expressing dopamine progenitor cells in NURR1 mutant mice. Exp. Cell Res. 253: 737-746.

Wang, Z., Benoit, G., Liu, J., Prasad, S., Aarnisalo, P., Liu, X., Xu, H., Walker, N.P.C., and Perlmann, T. 2003. Structure and function of Nurr1 identifies a class of ligand-independent nuclear receptors. Nature 423: 555-560.

Werme, M., Hermanson, E., Carmine, A., Buervenich, S., Zetterstrom, R.H., Thoren, P., Ogren, S.O., Olson, L., Perlmann, T., and Brene, S. 2003. Decreased ethanol preference and wheel running in Nurr1-deficient mice. Eur. J. Neurosci. 17: 2418-2424.

Wesierska, M., Dockery, C., and Fenton, A.A. 2005. Beyond memory, navigation, and inhibition: Behavioral evidence for hippocampus-dependent cognitive coordination in the rat. $J$. Neurosci. 25: 2413-2419.

Whishaw, I.Q. and Tomie, J.A. 1997. Perseveration on place reversals in spatial swimming pool tasks: Further evidence for place learning in hippocampal rats. Hippocampus 7: 361-370.

Wilson, T.E., Fahrner, T.J., Johnston, M., and Milbrandt, J. 1991. Identification of the DNA binding site for the NGFI-B by genetic selection in yeast. Science 252: 1296-1300.

Witta, J., Baffi, J.S., Palkovits, M., Mezey, E., Castillo, S.O., and Nikodem, V.M. 2000. Nigrostriatal innervation is preserved in Nurr1-null mice, although dopaminergic neuron precursors are arrested from terminal differentiation. Brain Res. Mol. Brain Res. 84: $67-78$.

Woronicz, J.D., Lina, A., Calnan, B.J., Szychowski, S., Cheng, L., and Winoto, A. 1995. Regulation of the Nur77 orphan steroid receptor in activation-induced apoptosis. Mol. Cell. Biol. 15: 6364-6376.

Xiao, Q., Castillo, S.O., and Nikodem, V.M. 1996. Distribution of messenger RNAs for the orphan nuclear receptors Nurr1 and Nur77 (NGFI-B) in adult rat brain using in situ hybridization. Neuroscience 75: 221-230.

Xing, G., Zhang, L., Heynen, T., Li, X.L., Smith, M.A., Weiss, S.R., Feldman, A.N., Detera-Wadleigh, S., Chuang, D.M., and Post, R.M. 1997. Rat nurr1 is prominently expressed in perirhinal cortex, and differentially induced in the hippocampal dentate gyrus by electroconvulsive vs. kindled seizures. Brain Res. Mol. Brain Res. 47: 251-261.

Xu, P.Y., Liang, R., Jankovic, J., Hunter, C., Zeng, Y.X., Ashizawa, T., Lai, D., and Le, W.D. 2002. Association of homozygous 7048G7049 variant in the intron six of Nurr1 gene with Parkinson's disease. Neurology 58: 881-884.

Yoshihara, Y., Kawasaki, M., Tamada, A., Nagata, S., Kagamiyama, H., and Mori, K. 1995. Overlapping and differential expression of BIG-2, BIG-1, TAG-1, and F3: Four members of an axon-associated cell adhesion molecule subgroup of the immunoglobulin superfamily. $J$. Neurobiol. 28: 51-69.

Zetterstrom, R.H., Solomin, L., Mitsiadis, T., Olson, L., and Perlmann, T. 1996. Retinoic X receptor heterodimerization and developmental expression distinguish the orphan nuclear receptors NGFI-B, Nurr1 and Nor1. Mol. Endocrinol. 10: 1656-1666.

Zetterstrom, R.H., Solomin, L., Jansson, L., Hoffer, B.J., Olson, L., and Perlmann, T. 1997. Dopamine neuron agenesis in Nurr1-deficient mice. Science 276: 248-250.

Received August 29, 2006; accepted in revised form September 1, 2006. 


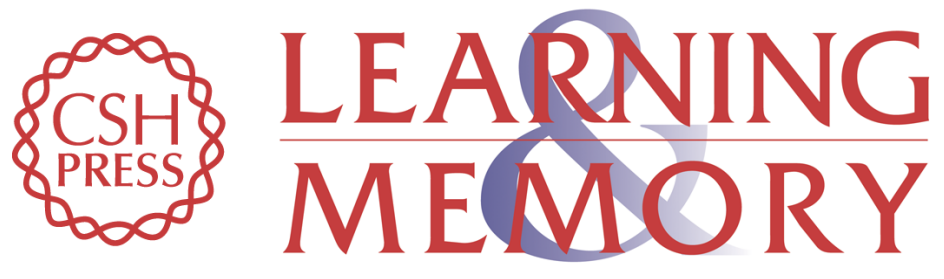

\section{Knockdown of Nurr1 in the rat hippocampus: Implications to spatial discrimination learning and memory}

Wanda I. Colón-Cesario, Michelle M. Martínez-Montemayor, Sohaira Morales, et al.

Learn. Mem. 2006, 13:

Access the most recent version at doi:10.1101//m.407706

References This article cites 93 articles, 28 of which can be accessed free at:

http://learnmem.cshlp.org/content/13/6/734.full.html\#ref-list-1

License

Email Alerting Receive free email alerts when new articles cite this article - sign up in the box at the Service top right corner of the article or click here. 